\title{
Quality of life after hepatic resection
}

P. Studer MD PhD'1, T. Horn' ${ }^{1}$ A. Haynes PhD², D. Candinas MD, V. M. Banz MD PhD ${ }^{1}$

${ }^{1}$ Department of Visceral Surgery and Medicine, Inselspital, Bern University Hospital, University of Bern, Switzerland

${ }^{2}$ CTU Bern, and Institute of Social and Preventive Medicine (ISPM), University of Bern, Switzerland

Original Article

Corresponding Author:

Vanessa M. Banz MD PhD

Department of Visceral Surgery and Medicine

Inselspital, University Hospital Bern

Freiburgstrasse

3010 Bern- $\mathrm{CH}$

vanessa.banz@insel.ch

Phone +41 3163259 48Footnote: The study was preregistered on ClinicalTrials.gov (NCT00681499). 
Abstract

Background:

Long-term quality of life (QoL) after liver resection (LR) is becoming increasingly important, as improvements in operative methods and perioperative care diminished in morbidity and mortality. In this study, postoperative QoL after LR for benign or malignant tumors was evaluated.

Methods:

In this single center study, QoL was evaluated prospectively using the EORTC QLQ-C30 and the liver-specific QLQ-LMC21 module preoperatively and 1, 3, 6 and 12 months after open or laparoscopic liver surgery.

Results:

Between 06/2007 and 01/2013 $n=188$ patients (malignant $n=130$, benign $n=58$ ) requiring major LR were included. Global health status was equally bad in both groups preoperatively and one month after LR. All patients showed an improvement in global health status at 3, 6 and 12 months post operation. Patients with benign tumors had better global health status than those with malignant tumors during the same periods $(p<0.001$, $p=0.002, p=0.006$, respectively). Patients with benign disease had better physical functioning scores at 3,6 and 12 months $(p=0.011, p=0.025, p=0.041)$ and lower fatigue score at 3,6 and 12 month compared to patients with malignant disease ( $p=0.001$, $p=0.002, p=0.002)$.

Conclusion:

This study confirms overall good QoL in patients undergoing LR for benign or malignant tumors which improved after surgery. Benign diseases were associated with better short and long-term QoL scores after LR. 


\section{Introduction}

Advances in surgical technique, anesthesiology and perioperative care have resulted in a decrease in postoperative mortality and morbidity after major hepatic surgery in specialized liver units ${ }^{1,2}$. As a result, the indications for and the extent of liver resections (LR) are being expanded ${ }^{3-5}$ with "patient-tailored" medicine and individualized resection strategies becoming increasingly important ${ }^{6}$. Due to these developments, including advances in adjuvant therapies, survival following LR for colorectal metastases as well as hepatocellular carcinoma (HCC) and cholangiocarcinoma, have increased in the last decades ${ }^{7-11}$. With reduced morbidity and increased post-hepatectomy survival, quality of life (QoL) becomes a leading issue and, particularly from a patient's point of view, as important as disease-free or overall survival ${ }^{12-14}$.

The term "Quality of life" (QoL) is used more frequently and tries to capture aspects of patient care and therapeutic goals previously not taken into account. QoL is subjective, multidimensional and dynamic over time, continuously fluctuating as it responds to life events. It includes a variety of domains and parameters, including physical, functional, social, and emotional well being. Interestingly, the sum of these components does not necessarily equal the subjective assessment of overall QoL ${ }^{15}$. Although patients with malignant diseases may more often complain about physical problems such as pain and restriction in physical activities compared to healthy individuals, they may nevertheless report a relatively good overall QoL. For health professionals and bystanders, there seems to be a discrepancy between reported health-related problems and the patient's personal judgment of overall health status. 
A retrospective study evaluating postoperative QoL in patients undergoing LR for benign or malignant liver tumors was published previously. Interestingly, the study did not show a correlation between poor prognosis and postoperative QoL, a finding that may come as a surprise, considering the nature of certain illnesses ${ }^{16}$. However, the retrospective design of the study and missing preoperative baseline QoL scores may have formed an impediment to correct interpretation of the data. Until now, no prospective studies have addressed the potential differences in long-term QoL in patients who have undergone LR for benign compared to malignant diseases ${ }^{17}$. The aim of this study was to investigate the effect of LR on QoL in patients undergoing surgery for benign or malignant tumors. 


\section{Materials and Methods}

This prospective study included patients who underwent open or laparoscopic LR for benign or malignant tumors at the Department of Visceral Surgery and Medicine at the Inselspital, University Hospital in Bern, Switzerland between 06/2007 - 01/2013. Major LR was defined as removal of $\geq 3$ neighboring segments. Exclusion criteria were age under 18 years, hepatobiliary surgeries only involving a liver biopsy, failure to perform a liver resection due to unexpected intraoperative findings or declined informed consent. All participants had a detailed preoperative briefing of the study and questionnaires involved. All participants in the study received the questionnaires preoperatively and after 1, 3, 6 and 12 months post surgery.

Quality of life was assessed using the European Organization for Research and Treatment of Cancer Quality of Life Questionnaire Core-30 (EORTC QLQ-C30, version 3.0). This cancer-specific QoL instrument was originally used in clinical trials involving patients with cancer. It contains five functional scales, including physical, role, social, emotional, and cognitive functions, as well as questions specifically aimed at checking for symptoms often reported by cancer patients (fatigue, nausea/vomiting, pain, dyspnea, insomnia, loss of appetite, constipation/diarrhea). The financial impact that the disease has on the patient is also taken into account. The questionnaire consists of 30 items of which 28 have a 4point scale; 2 items have a 7 -point scale for the overall QoL and health measure ${ }^{18}$. In addition the QLQ-LMC21 was used. This questionnaire consists of 21 items, each of which has a 4-point scale. The QLQ-LMC21 was initially designed to be used for patients with colorectal liver metastases because the general EORTC QLQ-C30 questionnaire did not adequately address problems specifically associated with hepatic metastases. Question 
categories include items on food intake, weight loss, pain, jaundice, fatigue, social problems, anxiety, and the influence of the disease on sexual activity ${ }^{19}$.

\section{Ethical considerations}

Ethical approval was obtained from the University of Bern ethical committee (institutional protocol number KEK 18/08). The study was also registered on ClinicalTrials.gov (NCT00681499). Written permission was obtained from all study participants. All eligible patients were given details of the study, including contact information of the researcher. Patients were informed about the aim of the study and were guaranteed anonymity and confidentiality with regard to the information given to the researcher. A licensing agreement was obtained from the EORTC for use of QLQ-C30, version 3.0 and the LMC21 questionnaires.

Statistical analysis

Primary and secondary outcomes based on multiply imputed data using repeated measures mixed-effects linear regression models adjusted for the baseline characteristics age, sex, jaundice, pruritus, weight loss, nausea, abdominal pain, lack of appetite, ASA Physical Status Classification System (used continuously), diabetes, cardiovascular disorders, pulmonary disorders and other disorders were analysed. The difference in scores between groups is presented with a corresponding $95 \% \mathrm{Cl}$ and $\mathrm{p}$ value.

Missing score data were accounted for by multiple imputation assuming missing data to be missing at random. Each score (i.e., global health status, physical functioning, emotional functioning, fatigue and pain) was imputed separately by linear regression 
methods based on the tumor type and the following variables: patient age at inclusion, hospital stay in days, ASA Physical Status Classification System (all used continuous), number of resected liver segments, death, relapse, sex, jaundice, pruritus, weight loss, nausea, abdominal pain, lack of appetite, diabetes, cardiovascular disorders, pulmonary disorders, other disorders, (neo)adjuvant chemotherapy, adjuvant radiotherapy, superficial infection, bilioma, pneumonia and other complications (all used categorical). In two cases, the number of segments and in four cases, hospital stay duration was missing. These were imputed along with global health status. Due to the absence of a monotone missing data pattern, we performed multiple imputation by chained equation was performed. In total, twenty imputed data sets were generated and analyzed as described above using Rubin's rules (Rubin DB. Multiple Imputation for Nonresponse in Surveys. New York: J Wiley \& Sons. 1987). Sensitivity analyses were based on complete data disregarding multiple imputation. All analyses were performed in STATA, release 13 (Stata Inc, College Station, TX). 


\section{Results}

A total of 196 patients undergoing liver resection between 06/2007 - 01/2013 were initially included in the study. Eight patients were subsequently excluded due to unexpected, intraoperative findings resulting in no liver resection being performed. Thus 130 patients with malignant disease and 58 with a benign pathology were available for final analysis (Table 1 and Table 2). Patients with benign tumors were more often female $(p=0.007)$ and younger $(p=0.001)$ compared to patients with malignant tumors. Furthermore patients with benign disease presented more frequently with nausea $(p=0.01)$, abdominal pain and a lower ASA score. Remaining baseline characteristics revealed no statistical differences between the groups (Table 1).

The amount of liver tissue removed was not different between the groups, with $53 \%$ of patients with benign tumors requiring major liver surgery compared to $65 \%$ of patients with malignant tumors $(p=0.223)$. Hospital length of stay was significantly longer in patients with malignant disease $(p=0.001)$, (Table 3).

The completeness of the EORTC questionnaires was analysed preoperatively and after 1, 3, 6 and 12 months (data not shown). The completeness 12 months after surgery dropped from $98 \%$ preoperatively in both groups to $69 \%$ in patients with malignant disease and remained high at $97 \%$ in patients with benign disease. Drop out in the early stages was mainly due to patients not willing to take part anymore (because filling in the two questionnaires was "too tedious"). At later time points other factors, such as patient death

or loss to follow-up, played a more important role. Eight (6\%) patients with malignant tumors deceased within the 12 month follow-up period. No postoperative mortality 
occurred in the benign disease group. In $n=68$ patients, recurrence of the underlying disease was noted.

For the analysis of the QLQ-C30 and QLQ-LMC21 questionnaire, the individual parameters were summarized in the following 5 categories: global health status, physical functioning, emotional function, fatigue and pain.

Global health status (as measured by the QLQ-C30 questionnaire) was equally low in patients with malignant and benign tumors in the preoperative setting and dropped similarly at one month after LR. Global health status improved over time in both groups, with the score gradually increasing again at 3, 6 and 12 months postoperatively. However, patients with benign disease showed a better global health status after 3, 6 and 12 months than to patients with malignant tumors $(p<0.001, p=0.002, p=0.006)$. Also, in both patient groups, global health status was better 12 months after surgery compared to preoperative values ( $p<0.001$ benign, $p=0.042$ malignant). Patients with recurrent disease did not present with worse global health status $(p=0.961)$ (Figure 1a). Similar results were found in the QLQ-C30 category physical functioning. Both patient groups recovered after an initial drop one month after surgery. Patients with benign disease presented with better physical functioning scores at 3,6 and 12 months $(p=0.011, p=0.025, p=0.041)$ compared to patients with malignant diseases (Figure 1b). Emotional function according to the QLQC30 score was similar in both groups at baseline. Unlike the global health score and physical functioning score, there was no initial decrease in the emotional function score. The emotional functioning score continuously increased up to 12 months after LR, being identical in both groups at the 12-month time point. At 3 and 6 months, patients with benign disease presented with a slightly better emotional functioning score compared to patients with malignant disease $(p=0.005, p=0.019)$ (Figure 1c). Fatigue as a symptom was 
identical in both groups at baseline. Fatigue scores increased to a similar extent one month after surgery in all patients and decreased to preoperative values in patients with malignant tumors. However, in patients with benign tumors fatigue was less pronounced at 3, 6 and 12 month compared to patients with malignant disease $(p=0.001, p=0.002$, $p=0.002$ ) but also lower compared to baseline (Figure 1d). Mean scores for pain were identical in both groups at baseline, 1, 6 and 12 months. One month after LR, pain scores were still increased in all patients compared to preoperatively, with patients with malignant tumors having a significantly higher pain score, 3 months postoperatively compared to patients with LR for benign tumors $(p=0.005)$, (Figure $1 e)$.

\section{Discussion}

In this prospective study covering a longer time period quality of life in patients undergoing liver resection for benign or malignant tumors was evaluated. Liver resection was found to be safe and showed an acceptable morbidity and low mortality as previously reported 1. As might be expected, self-reported overall quality of life, as measured by the global health status, showed a drop in the first month after surgery for both patient groups. It is essential that patients are informed preoperatively about this, reassuring them that QoL improves for the majority of patients after the first month. Already at the 3-month postoperative time-point, QoL increased substantially and continued to do so during the entire study period. For patients with benign pathologies, this finding is in line with the high percentage of symptom relief after liver resection previously demonstrated ${ }^{20}$. Parallel to what can be observed in many specialized liver units worldwide ${ }^{21,22}$, minimally invasive 
liver resections are increasingly becoming gold standard in the present authors' unit, making up the majority of hepatic resections in the currently. However, during the study period, patients still mainly underwent open hepatic surgery. Too low patient numbers concerning laparoscopic LR precluded statistical analyses, but the drop in self-reported QoL at one month postoperative may be expected to be less in patients undergoing laparoscopic resections ${ }^{23}$.

Some of the patients not answering the one month questionnaire were still in hospital at the given time point. It may seem fair to assume, that their self-reported overall QoL might be worse than the one actually reported. However, and surprisingly, patients suffering from postoperative complications who answered the questionnaires at the one month time period showed QoL scores that were not statistically different from those patients with an unproblematic postoperative course. This goes against what treating surgeons and physicians might expect. However, as has been shown by others ${ }^{24,25}$, self-reported QoL remains subjective, taking into account a multitude of equations. There are not solely based on measurable factors such as disease entity (malignant versus benign) or the presence or absence of physical restrictions and limitations.

Interestingly, preoperative, that is "base-line" QoL was very similar in both patient groups, as were some of the main parameters analyzed by the QLQ-C30 and QLQ-LCM21 (physical function, emotional functioning, fatigue and pain). This too seems contraintuitive, as one might expect patients with malignant diagnoses to fare worse. However, this may in part be explained by the fact that patients with benign tumors more frequently reported nausea and abdominal pain at the time point of their first consultation. It also may be explained by the patient's general attitude and expectations towards the planned surgical intervention in case of a malignant diagnosis. Patients with a malignant tumor will 


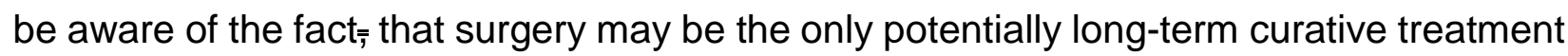
strategy. Knowing that they qualify for surgery may thus result in an improved, selfreported overall QoL. Similar findings have been reported by others ${ }^{26}$.

The findings of this study are limited by its single center design, restricting generalisation of the results. Also, patients with malignant diseases not responding to the survey may have had poor QoL, potentially adding a bias to the results presented. Finally, the sample size for this study was calculated for the overall, self-reported QoL but not for every subanalysis performed.

\section{Acknowledgments}

We would like to thank Mrs Veronika Fiege MPH from the Clinical Trials Unit Bern for help with the statistical analyses. 


\section{References}

1. Virani S, Michaelson JS, Hutter MM, Lancaster RT, Warshaw AL, Henderson WG, et al. Morbidity and mortality after liver resection: results of the patient safety in surgery study. Journal of the American College of Surgeons 2007; 204: 1284-1292.

2. Hughes MJ, McNally S, Wigmore SJ. Enhanced recovery following liver surgery: a systematic review and meta-analysis. HPB (Oxford) 2014; 16: 699-706.

3. Chun YS, Vauthey JN, Ribero D, Donadon M, Mullen JT, Eng C, et al. Systemic chemotherapy and two-stage hepatectomy for extensive bilateral colorectal liver metastases: perioperative safety and survival. Journal of gastrointestinal surgery : official journal of the Society for Surgery of the Alimentary Tract 2007; 11: 1498-1504; discussion 1504-1495.

4. Schiesser M, Chen JW, Maddern GJ, Padbury RT. Perioperative morbidity affects long-term survival in patients following liver resection for colorectal metastases. Journal of gastrointestinal surgery : official journal of the Society for Surgery of the Alimentary Tract 2008; 12: 1054-1060.

5. de'Angelis N, Pascal G, Salloum C, Lahat E, Ichai P, Saliba F, et al. Central Hepatectomy versus Extended Hepatectomy for Malignant Tumors: A Propensity Score Analysis of Postoperative Complications. World journal of surgery 2016; 40: 2745-2757. 6. van Kessel CS, van Leeuwen MS, van Hillegersberg R, Rinkes IH, van den Bosch MA, Molenaar IQ. Patient tailored resection planning in patients undergoing liver surgery for colorectal liver metastases; how and why should you do it? Journal of gastrointestinal surgery : official journal of the Society for Surgery of the Alimentary Tract 2013; 17 : 1836-1849. 
7. Adam R, Delvart V, Pascal G, Valeanu A, Castaing D, Azoulay D, et al. Rescue surgery for unresectable colorectal liver metastases downstaged by chemotherapy: a model to predict long-term survival. Annals of surgery 2004; 240: 644-657; discussion 657-648.

8. Ng KK, Vauthey JN, Pawlik TM, Lauwers GY, Regimbeau JM, Belghiti J, et al. Is hepatic resection for large or multinodular hepatocellular carcinoma justified? Results from a multi-institutional database. Ann Surg Oncol 2005; 12: 364-373.

9. Fong Y, Fortner J, Sun RL, Brennan MF, Blumgart LH. Clinical score for predicting recurrence after hepatic resection for metastatic colorectal cancer: analysis of 1001 consecutive cases. Annals of surgery 1999; 230: 309-318; discussion 318-321. 10. Sasaki K, Andreatos N, Margonis GA, He J, Weiss M, Johnston F, et al. The prognostic implications of primary colorectal tumor location on recurrence and overall survival in patients undergoing resection for colorectal liver metastasis. J Surg Oncol 2016; 114: 803-809.

11. Ariizumi S, Kotera Y, Katagiri S, Nakano M, Nakanuma Y, Saito A, et al. Longterm survival of patients with cholangiolocellular carcinoma after curative hepatectomy. Ann Surg Oncol 2014; 21 Suppl 3: S451-458.

12. Slevin ML. Quality of life: philosophical question or clinical reality? Bmj 1992; 305: 466-469.

13. Lei JY, Yan LN, Wang WT, Zhu JQ, Li DJ. Health-Related Quality of Life and Psychological Distress in Patients With Early-Stage Hepatocellular Carcinoma After Hepatic Resection or Transplantation. Transplant Proc 2016; 48: 2107-2111. 
14. Rees JR, Blazeby JM, Fayers P, Friend EA, Welsh FK, John TG, et al. Patientreported outcomes after hepatic resection of colorectal cancer metastases. J Clin Oncol 2012; 30: 1364-1370.

15. Cella DF. Quality of life: concepts and definition. Journal of pain and symptom management 1994; 9: 186-192.

16. Banz VM, Inderbitzin D, Fankhauser R, Studer P, Candinas D. Long-term quality of life after hepatic resection: health is not simply the absence of disease. World journal of surgery $2009 ; 33: 1473-1480$.

17. Kamphues C, Engel S, Denecke T, Bova R, Hippler-Benscheidt M, Puhl G, et al. Safety of liver resection and effect on quality of life in patients with benign hepatic disease: single center experience. BMC Surg 2011; 11: 16.

18. Aaronson NK, Ahmedzai S, Bergman B, Bullinger M, Cull A, Duez NJ, et al. The European Organization for Research and Treatment of Cancer QLQ-C30: a quality-oflife instrument for use in international clinical trials in oncology. Journal of the National Cancer Institute 1993; 85: 365-376.

19. Kavadas V, Blazeby JM, Conroy T, Sezer O, Holzner B, Koller M, et al. Development of an EORTC disease-specific quality of life questionnaire for use in patients with liver metastases from colorectal cancer. European journal of cancer 2003;

39: $1259-1263$.

20. van Rosmalen BV, Bieze M, Besselink MG, Tanis P, Verheij J, Phoa SS, et al. Long-term outcomes of resection in patients with symptomatic benign liver tumours. HPB (Oxford) 2016; 18: 908-914.

21. Wakabayashi G, Cherqui D, Geller DA, Buell JF, Kaneko H, Han HS, et al. Recommendations for laparoscopic liver resection: a report from the second 
international consensus conference held in Morioka. Annals of surgery 2015; 261: 619629.

22. Kawaguchi Y, Hasegawa K, Wakabayashi G, Cherqui D, Geller DA, Buell JF, et al. Survey results on daily practice in open and laparoscopic liver resections from 27 centers participating in the second International Consensus Conference. J Hepatobiliary Pancreat Sci 2016; 23: 283-288.

23. Dowson HM, Ballard K, Gage H, Jackson D, Williams P, Rockall TA. Quality of life in the first 6 weeks following laparoscopic and open colorectal surgery. Value Health 2013; 16: 367-372.

24. Osoba D, Rodrigues G, Myles J, Zee B, Pater J. Interpreting the significance of changes in health-related quality-of-life scores. J Clin Oncol 1998; 16: 139-144.

25. King MT. The interpretation of scores from the EORTC quality of life questionnaire QLQ-C30. Qual Life Res 1996; 5: 555-567.

26. Bottomley A. The cancer patient and quality of life. Oncologist 2002; 7: 120-125. 


\section{Figure Legends}

Table 1: Baseline characteristics of included patients $(\mathrm{N}=188)$ for each tumor type

Table 2: Baseline table of tumor entities

Table 3: Procedural characteristics and complications of included patients $(\mathrm{N}=188)$ for each tumor type

Figure 1a-e: Scoring results of the QLQ-C30 and the QLQ-LMC21 
Table 1: Baseline characteristics of included patients $(\mathrm{N}=188)$ for each tumor type

\begin{tabular}{|c|c|c|c|c|}
\hline & $\begin{array}{l}\text { All tumor groups } \\
(n=188)\end{array}$ & $\begin{array}{l}\text { Patients with } \\
\text { malignant tumors } \\
(n=130)\end{array}$ & $\begin{array}{l}\text { Patients with } \\
\text { benign tumors } \\
(n=58)\end{array}$ & $p$ value \\
\hline Sex (female) & $88(47 \%)$ & $52(40 \%)$ & $36(62 \%)$ & 0.007 \\
\hline Age & $58.0 \pm 13.4$ & $61.7 \pm 10.6$ & $49.8 \pm 15.2$ & $<0.001$ \\
\hline $\begin{array}{l}\text { Jaundice } \\
\text { No }\end{array}$ & $164(87 \%)$ & $114(88 \%)$ & $50(86 \%)$ & 0.778 \\
\hline Yes & $24(13 \%)$ & $16(12 \%)$ & $8(14 \%)$ & \\
\hline Pruritus & & & & 0.099 \\
\hline No & $171(91 \%)$ & $115(88 \%)$ & $56(97 \%)$ & \\
\hline Yes & $17(9 \%)$ & $15(12 \%)$ & $2(3 \%)$ & \\
\hline Weight loss & & & & 0.513 \\
\hline No & $140(74 \%)$ & 95 (73\%) & $45(78 \%)$ & \\
\hline Yes & $48(26 \%)$ & $35(27 \%)$ & $13(22 \%)$ & \\
\hline Nausea & & & & $<0.001$ \\
\hline No & $159(85 \%)$ & $118(91 \%)$ & $41(71 \%)$ & \\
\hline Yes & $29(15 \%)$ & $12(9 \%)$ & $17(29 \%)$ & \\
\hline Abdominal pain & & & & $<0.001$ \\
\hline No & $128(68 \%)$ & $101(78 \%)$ & $27(47 \%)$ & \\
\hline Yes & $60(32 \%)$ & $29(22 \%)$ & $31(53 \%)$ & \\
\hline Loss of appetite & & & & 0.096 \\
\hline No & 147 (78\%) & $106(82 \%)$ & $41(71 \%)$ & \\
\hline Yes & $41(22 \%)$ & $24(18 \%)$ & 17 (29\%) & \\
\hline ASA Physical Status Classification System & & & & $<0.001$ \\
\hline Normal healthy patient & $17(9 \%)$ & $6(5 \%)$ & $11(19 \%)$ & \\
\hline Patients with mild systemic disease & $101(54 \%)$ & $65(50 \%)$ & $36(62 \%)$ & \\
\hline Patients with severe systemic disease & $67(36 \%)$ & $57(44 \%)$ & $10(17 \%)$ & \\
\hline $\begin{array}{l}\text { Patients with severe systemic disease that is a } \\
\text { constant threat to life }\end{array}$ & $3(2 \%)$ & $2(2 \%)$ & $1(2 \%)$ & \\
\hline $\begin{array}{l}\text { Moribund patients who are not expected to } \\
\text { survive without the operation }\end{array}$ & $0(0 \%)$ & $0(0 \%)$ & $0(0 \%)$ & \\
\hline $\begin{array}{l}\text { A declared brain-dead patient whose organs are } \\
\text { being removed for donor purposes }\end{array}$ & $0(0 \%)$ & $0(0 \%)$ & $0(0 \%)$ & \\
\hline Diabetes & & & & 0.820 \\
\hline No & $163(87 \%)$ & $112(86 \%)$ & $51(88 \%)$ & \\
\hline Yes & $25(13 \%)$ & $18(14 \%)$ & $7(12 \%)$ & \\
\hline Cardiovascular disorders & & & & 0.109 \\
\hline No & $113(60 \%)$ & $73(56 \%)$ & $40(69 \%)$ & \\
\hline Yes & $75(40 \%)$ & $57(44 \%)$ & $18(31 \%)$ & \\
\hline Pulmonary disorders & & & & 0.177 \\
\hline No & $161(86 \%)$ & $108(83 \%)$ & $53(91 \%)$ & \\
\hline Yes & 27 (14\%) & $22(17 \%)$ & $5(9 \%)$ & \\
\hline Kidney disease & & & & 0.440 \\
\hline No & $181(96 \%)$ & $124(95 \%)$ & $57(98 \%)$ & \\
\hline Yes & $7(4 \%)$ & $6(5 \%)$ & $1(2 \%)$ & \\
\hline Other disorders & & & & 0.266 \\
\hline No & $108(57 \%)$ & $71(55 \%)$ & $37(64 \%)$ & \\
\hline Yes & $80(43 \%)$ & $59(45 \%)$ & $21(36 \%)$ & \\
\hline
\end{tabular}


Data are n (\%) or mean \pm SD. P value: Fisher's exact test or t-test as appropriate. ${ }^{*}$ American Society of Anesthesiologists. 
Table 2. Tumor types

\begin{tabular}{lccc}
\hline & All patients & Malignant & Benign \\
& $\mathrm{N}=196$ & $\mathrm{~N}=138$ & $\mathrm{~N}=58$ \\
\hline Diagnosis & $\mathrm{n}=196$, & $\mathrm{n}=138$, & $\mathrm{n}=58$, \\
Benign (excl. echinococcosis) & $38(19 \%)$ & $0(0 \%)$ & $38(66 \%)$ \\
Cholangiocarcinoma (incl. hilar cholangiocarcinoma) & $17(9 \%)$ & $17(12 \%)$ & $0(0 \%)$ \\
Colorectal liver metastases & $57(29 \%)$ & $57(41 \%)$ & $0(0 \%)$ \\
Echinococcosis & $20(10 \%)$ & $0(0 \%)$ & $20(34 \%)$ \\
Hepatocellular carcinoma & $32(16 \%)$ & $32(23 \%)$ & $0(0 \%)$ \\
Other liver metastases (excl. colorectal) & $25(13 \%)$ & $25(18 \%)$ & $0(0 \%)$ \\
Other primary malignant liver tumors & $5(3 \%)$ & $5(4 \%)$ & $0(0 \%)$ \\
Colorectal liver metastases \& Hepatocellular carcinoma & $2(1 \%)$ & $2(1 \%)$ & $0(0 \%)$ \\
\hline
\end{tabular}


Table 3: Procedural characteristics and complications of included patients $(\mathrm{N}=188)$ for each tumor type

\begin{tabular}{|c|c|c|c|c|}
\hline & All tumor groups & $\begin{array}{l}\text { Patients with } \\
\text { malignant tumor }\end{array}$ & $\begin{array}{l}\text { Patients with benign } \\
\text { tumor }\end{array}$ & $\mathrm{p}$ Value \\
\hline & $\mathrm{N}=188$ & $N=130$ & $\mathrm{~N}=58$ & \\
\hline Number of resected liver segments & & & & 0.223 \\
\hline$<3$ segments (minor liver surgery) & $71(38 \%)$ & $44(34 \%)$ & $27(47 \%)$ & \\
\hline$\geq 3$ segments (major liver surgery) & $115(61 \%)$ & $84(65 \%)$ & $31(53 \%)$ & \\
\hline Missing & $2(1 \%)$ & $2(2 \%)$ & $0(0 \%)$ & \\
\hline Hospital stay (days) & $15.6 \pm 13.0$ & $18.1 \pm 14.4$ & $10.0 \pm 6.4$ & $<0.001$ \\
\hline (Neo)adjuvant chemotherapy & & & & $<0.001$ \\
\hline No & $126(67 \%)$ & $69(53 \%)$ & $57(98 \%)$ & \\
\hline Yes & $62(33 \%)$ & $61(47 \%)$ & $1(2 \%)$ & \\
\hline Adjuvant radiotherapy & & & & 0.010 \\
\hline No & $175(93 \%)$ & $117(90 \%)$ & $58(100 \%)$ & \\
\hline Yes & $13(7 \%)$ & $13(10 \%)$ & $0(0 \%)$ & \\
\hline Superficial infection & & & & 0.128 \\
\hline No & $168(89 \%)$ & $113(87 \%)$ & $55(95 \%)$ & \\
\hline Yes & $20(11 \%)$ & $17(13 \%)$ & $3(5 \%)$ & \\
\hline Deep infection & & & & 1.000 \\
\hline No & $180(96 \%)$ & $124(95 \%)$ & $56(97 \%)$ & \\
\hline Yes & $8(4 \%)$ & $6(5 \%)$ & $2(3 \%)$ & \\
\hline Bilioma & & & & 0.515 \\
\hline No & $160(85 \%)$ & $109(84 \%)$ & $51(88 \%)$ & \\
\hline Yes & $28(15 \%)$ & $21(16 \%)$ & $7(12 \%)$ & \\
\hline Hemorrhage/ hematoma & & & & 1.000 \\
\hline No & $178(95 \%)$ & $123(95 \%)$ & $55(95 \%)$ & \\
\hline Yes & $10(5 \%)$ & $7(5 \%)$ & $3(5 \%)$ & \\
\hline Thrombosis & & & & 0.523 \\
\hline No & $186(99 \%)$ & $129(99 \%)$ & $57(98 \%)$ & \\
\hline Yes & $2(1 \%)$ & $1(1 \%)$ & $1(2 \%)$ & \\
\hline Pulmonary embolism & & & & 1.000 \\
\hline No & $186(99 \%)$ & $128(98 \%)$ & $58(100 \%)$ & \\
\hline Yes & $2(1 \%)$ & $2(2 \%)$ & $0(0 \%)$ & \\
\hline Pneumonia & & & & 1.000 \\
\hline No & 177 (94\%) & $122(94 \%)$ & $55(95 \%)$ & \\
\hline Yes & $11(6 \%)$ & $8(6 \%)$ & $3(5 \%)$ & \\
\hline Other complications & & & & 0.001 \\
\hline No & $139(74 \%)$ & 87 (67\%) & $52(90 \%)$ & \\
\hline
\end{tabular}


Yes

Surgical reintervention

No

Yes

Missing

Data are
49 (26\%)

$170(90 \%)$

$17(9 \%)$

$1(1 \%)$
43 (33\%)

$15(12 \%)$

$1(1 \%)$
$6(10 \%)$

0.119

56 (97\%)

$2(3 \%)$

$0 \quad(0 \%)$ 

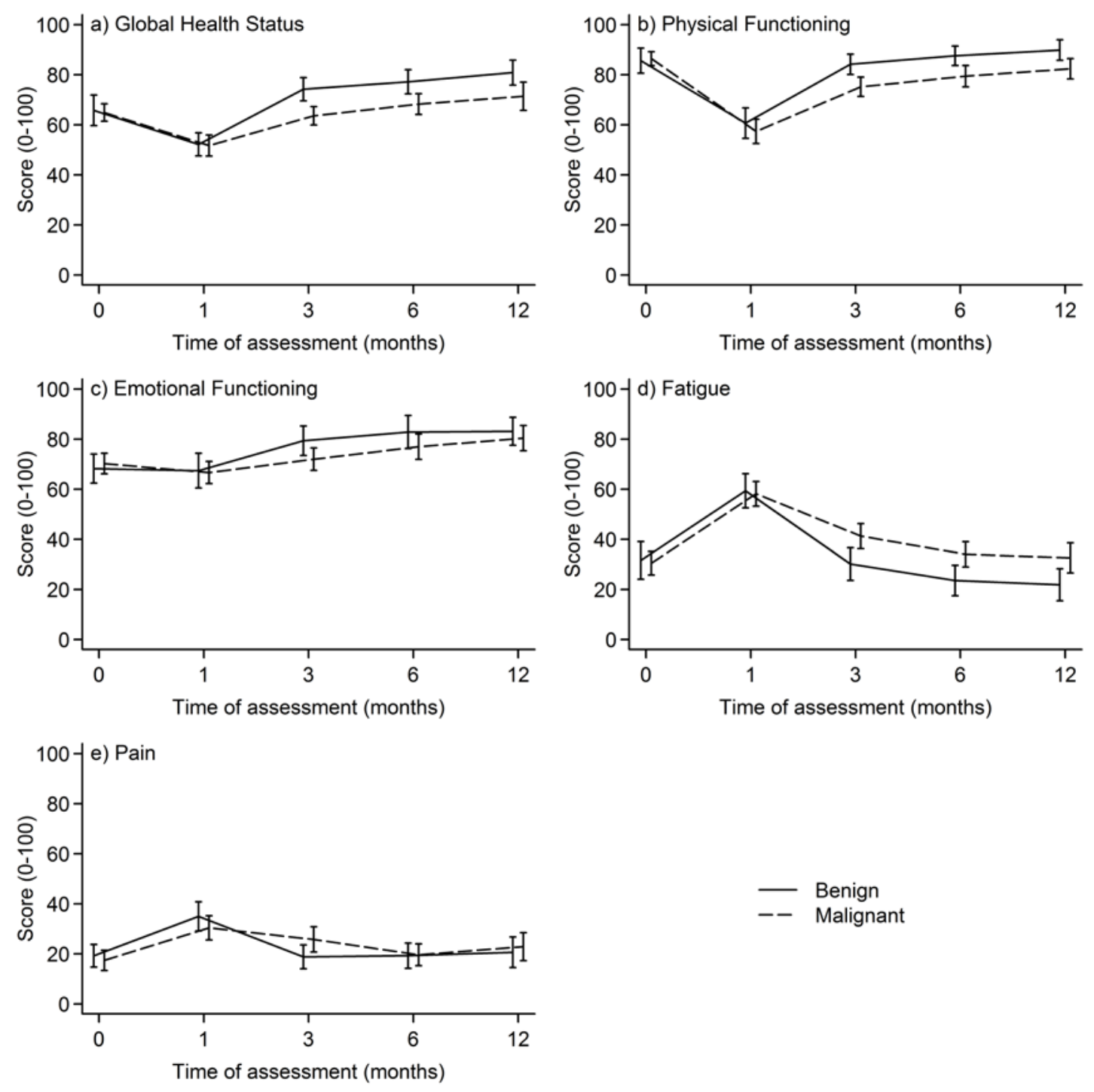

Figure 1 a-f: Mean scores with $95 \%$ confidence intervals based on imputed data.

All of the scales and single-item measures range in score from 0 to 100 . A high scale score represents a higher response level. Thus a high score for the global health status / QoL represents a high QoL, a high score for a functional scale (e.g., physical functioning, emotional functioning) represents a high / healthy level of functioning, but a high score for a symptom scale / item (e.g., fatigue) represents a high level of symptomatology / problems. 